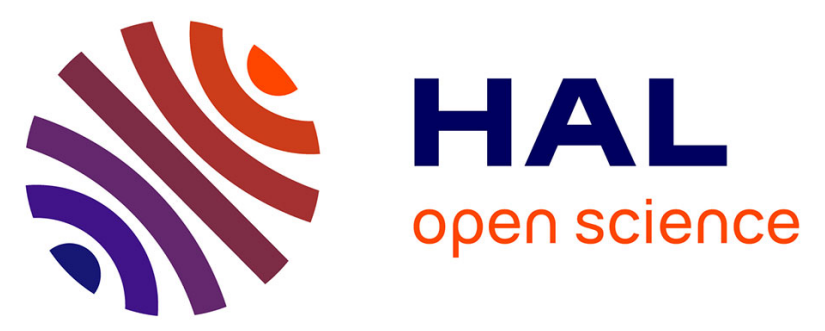

\title{
Postexercise cooling interventions and the effects on exercise-induced heat stress in a temperate environment
}

Christophe Hausswirth, Rob Duffield, Hervé Pournot, François Bieuzen, Julien Louis, Jeanick Brisswalter, Olivier Castagna

\section{- To cite this version:}

Christophe Hausswirth, Rob Duffield, Hervé Pournot, François Bieuzen, Julien Louis, et al.. Postexercise cooling interventions and the effects on exercise-induced heat stress in a temperate environment. Applied Physiology, Nutrition, and Metabolism, 2012, 37 (5), pp.965-975. 10.1139/h2012-077 . hal01828757

\section{HAL Id: hal-01828757 \\ https://hal-insep.archives-ouvertes.fr/hal-01828757}

Submitted on 3 Jul 2018

HAL is a multi-disciplinary open access archive for the deposit and dissemination of scientific research documents, whether they are published or not. The documents may come from teaching and research institutions in France or abroad, or from public or private research centers.
L'archive ouverte pluridisciplinaire HAL, est destinée au dépôt et à la diffusion de documents scientifiques de niveau recherche, publiés ou non, émanant des établissements d'enseignement et de recherche français ou étrangers, des laboratoires publics ou privés. 


\title{
Post-exercise cooling interventions and the effects on exercise-induced heat stress in a temperate environment.
}

\author{
Christophe HAUSSWIRTH ${ }^{1}$, Rob DUFFIELD ${ }^{2}$, Hervé POURNOT ${ }^{1,3}$, François BIEUZEN ${ }^{1}$, \\ Julien LOUIS ${ }^{1,3}$, Jeanick BRISSWALTER ${ }^{3}$, Olivier CASTAGNA ${ }^{4}$ \\ ${ }^{1}$ INSEP (National Institute of Sport, for Expertise and Performance) - Research Department 11, avenue du \\ Tremblay 75012 Paris (France) \\ ${ }^{2}$ School of Human Movement Studies, Charles Sturt University Panorama Ave, Bathurst, NSW, 2795(Australia) \\ ${ }^{3}$ Laboratory of Human Motricity, Education Sport and Health, University of Nice Sophia-Antipolis, Nice, \\ (France) \\ ${ }^{4}$ Institut de Recherche Biomédicale aux Armées, (IRBA) -BP 20548-83041 TOULON cedex 9 (France) \\ Corresponding author: \\ Dr. Christophe HAUSSWIRTH, PhD, \\ INSEP - French National Institute of Sport, Expertise and Performance Research Department 11, avenue du \\ Tremblay 75012 Paris (France) Tel: 0033141744385 \\ Email: christophe.hausswirth@insep.fr
}

Article publié : Hausswirth C, Duffield R, Pournot H, et al. Postexercise cooling interventions and the effects on exercise-induced heat stress in a temperate environment. Appl. Physiol. Nutr. Metab. 2012;37(5):965-975. http://dx.doi.org/10.1139/h2012-077

\begin{abstract}
:
The aim of this study was to examine the effects of cool water immersion $\left(20^{\circ} \mathrm{C}\right.$; CWI), wearing a cooling jacket ('Cryovest'; V) and a passive control (PAS) as recovery methods on physiological and thermoregulatory responses between two exercise bouts in temperate conditions. Nine well-trained male cyclists performed two successive bouts of $45 \mathrm{~min}$ of endurance cycling exercise in a temperate environment $\left(20^{\circ} \mathrm{C}\right)$ separated by $25 \mathrm{~min}$ of the respective recovery interventions. Capillary blood samples were obtained to measure lactate (La-), Sodium $\left(\mathrm{Na}^{+}\right)$, Bicarbonate $\left(\mathrm{HCO}_{3}{ }^{-}\right)$concentrations and $\mathrm{pH}$, whilst body mass loss (BML), core temperature (Tcore), skin temperature (Tskin), heart rate (HR), oxygen uptake $\left(\dot{\mathrm{VO}}_{2}\right)$ and minute ventilation $\left(\dot{\mathrm{V}}_{\mathrm{E}}\right)$, were measured before
\end{abstract}


(Pre), immediately after the first exercise bout (Ex1), the recovery (R) and after the second exercise bout (Ex2). V and CWI both resulted in a reduction of Tskin at $\mathrm{R}\left(-2.1 \pm 0.01^{\circ} \mathrm{C}\right.$ and $-11.6 \pm 0.01^{\circ} \mathrm{C}$, respectively, $\left.\mathrm{P}<0.01\right)$. Despite no difference in final values post Ex2 $(\mathrm{P}>0.05), \mathrm{V}$ attenuated the rise in $\mathrm{HR}, \dot{\mathrm{V}}_{\mathrm{E}}$ and $\dot{\mathrm{V}} 2$ from Ex1 to Ex2, while Tcore, and Tskin were significantly lower following the second session $(\mathrm{P}<0.05)$. Further, CWI was also beneficial in lowering Tcore, Tskin and BML while a rise in $\mathrm{Na}^{+}$was observed following $\operatorname{Ex} 2(\mathrm{P}<0.05)$. Overall results indicate that cooling interventions (Vand CWI) following exercise in a temperate environment provide a reduction in thermal strain during ensuing exercise bouts.

Key words:Recovery, Subsequent exercise, Cold, Hydrostatic pressure, Thermoregulation, Cycling

\section{Résumé}

Le but de cette étude était d'examiner les effets de l'immersion en eau froide $\left(20^{\circ} \mathrm{C}\right.$; CWI), d'une veste réfrigérée (Cryovest; $\mathrm{V}$ ) et d'une condition passive de contrôle (PAS) comme méthodes de récupération sur les réponses physiologiques et thermorégulatrices entre deux exercices effectués dans des conditions thermiques tempérées. Neuf cyclistes masculins bien entraînés ont effectué deux sessions de cyclisme de 45 minutes à une intensité sous-maximale dans une salle tempérée $\left(20^{\circ} \mathrm{C}\right)$, séparées par $25 \mathrm{~min}$ de récupération. Des échantillons de sang étaient prélevés pour mesurer les concentrations en lactate $\left(\mathrm{La}^{-}\right)$, sodium $\left(\mathrm{Na}^{+}\right)$, et bicarbonates $\left(\mathrm{HCO}_{3}{ }^{-}\right)$, le $\mathrm{pH}$, et la perte de masse corporelle (BML), la température moyenne du corps (Tbody), la température centrale (Tcore), la température de la peau (Tskin), la fréquence cardiaque (HR), la consommation en oxygène ( $\left.\dot{\mathrm{VO}}_{2}\right)$, le débit ventilatoire ( $\dot{\mathrm{V}}_{\mathrm{E}}$ ), la pression systolique (Sys BP) et la pression artérielle diastolique (Dia BP) étaient mesurés avant (Pré), immédiatement après le premier exercice $(\mathrm{Ex} 1)$, après la récupération $(\mathrm{R})$ et après le deuxième exercice (Ex2). L'utilisation de $\mathrm{V}$ et de CWI induisaient une réduction de Tskin après $\mathrm{R}\left(-2,1 \pm 0,01^{\circ} \mathrm{C}\right.$ et $-11,6 \pm$ $0,01^{\circ} \mathrm{C}$, respectivement, $\left.\mathrm{P}<0,01\right)$. L'utilisation de $\mathrm{V}$ permettait de réduire l'augmentation de $\mathrm{HR}, \dot{\mathrm{V}}_{\mathrm{E}}$ et $\dot{\mathrm{V}} \mathrm{O}_{2}$ entre les deux exercices, ainsi que de réduire $\mathrm{La}^{-}$, Tcore et Tskin à la fin du deuxième exercice $(\mathrm{P}<0,05)$. $\mathrm{CWI}\left(20^{\circ} \mathrm{C}\right)$ permettait également de diminuer $\mathrm{La}^{-}$, Tcore, Tskin et BML tandis qu'une élévation de $\mathrm{Na}^{+}$était observée $(\mathrm{P}<0,05)$. En conclusion, les résultats de cette étude indiquent un effet bénéfique des stratégies de refroidissement (Vet CWI) entre deux exercices d'endurance effectués dans un environnement tempéré sur la réduction de la contrainte thermique lors du second exercice.

Mots Clés: Récupération, Froid, Pression hydrostatique, Thermorégulation, Cyclisme 


\section{Introduction}

The effects of pre- and post-exercise cooling on performance and recovery, respectively, receive continued interest in research and practical settings; specifically in the case of athletes at risk of environmental or exercise-induced heat stress (Brade et al. 2010; Schmidt and Bruck 1981; Vaile et al. 2008). Researchers have investigated a range of methods to cool the body, where both core and skin temperatures were measured to determine the most effective techniques for cooling individuals prior to or following exercise (Duffield et al. 2003; Vaile et al. 2008). The most common methods reported in the literature are: exposure to cold air (Kruk et al. 1990a), application of cold packs (White et al. 2003), wearing cooling jackets (Castle et al. 2006; Duffield et al. 2003), water immersion (Pournot et al. 2011; Vaile et al. 2008; Vaile et al. 2011), ice slurry ingestion (Siegel et al. 2012), cold towels (Duffield et al. 2009) or a combination of these methods (Castle et al. 2006; Ross et al. 2011). Pre-cooling may aid endurance performance by lowering the physiological and thermoregulatory load of exercise, allowing an increased work capacity before critical physiological or perceptual limits are reached (Cheuvront et al. 2010; Schmidt and Bruck 1981; Siegel et al. 2010). Similarly, post-exercise cooling is reported to be beneficial for subsequent performance due to a faster reduction of exercise-induced thermoregulatory and physiological loads (Buchheit et al. 2009; Vaile et al. 2011; Webster et al. 2005). A majority of studies report beneficial effects of pre- and post-exercise cooling on performance in warm environmental conditions, hypothesized to result from the attenuation of thermal load (Castle et al. 2006; Duffield and Marino 2007; Sleivert et al. 2001). However, many sporting events are conducted in cool to temperate conditions, possibly questioning the need for such interventions when the exogenous heat stress is reduced (Galloway and Maughan 1997; Kenny et al. 1997). Furthermore, while successful cooling interventions seem related to a general volume effect (Walsh and Whitham 2006), questions remain as to whether the observed benefits from cold water immersion are due to temperature or hydrostatic effects from immersion (Wilcock et al. 2006). Moreover, the practicality of portable interventions (e.g.cooling jackets) over immersion techniques also results in questions of benefits versus practical logistics in field environments. Accordingly, this study aimed to investigate the effects of different cooling interventions on physiological responses during post-exercise recovery and ensuing subsequent exercise in temperate environmental conditions.

Exercise-induced increases in metabolic heat load are a considerable challenge to temperature homeostasis, and may ultimately impair physical performance (White et al. 2003). High core and skin temperatures (Tcore and Tskin) may exacerbate cardiovascular and thermoregulatory load, potentially limiting prolonged aerobic exercise (Cheuvront et al. 2010; Sawka et al. 2011), regardless of environmental conditions (Galloway and Maughan 
1997; Webster et al. 2005). Indeed, a similar maximal rectal temperature $\left(39.5^{\circ} \mathrm{C}\right)$ was recorded in elite cyclists following a 30 min time trial in warm $\left(32^{\circ} \mathrm{C}\right)$ or temperate $\left(23^{\circ} \mathrm{C}\right)$ conditions (Tatterson et al. 2000). Such thermal load can have a residual effect on subsequent exercise sessions performed on the same day, even in a temperate environment (Kruk et al. 1990b; Sawka et al. 1979). For example, a higher Tcore, heart rate (HR), and oxygen uptake $\left(\dot{\mathrm{VO}}_{2}\right)$ were reported in subsequent exercise sessions, even following 30-180 min of recovery (Kruk et al. 1990b; Ronsen et al. 2004; Sawka et al. 1979). Therefore, since absolute heat storage may limit exercise performance at a given intensity, it seems beneficial to reduce the thermal load prior to the start of exercise (pre-cooling) (Arngrimsson et al. 2004; Hasegawa et al. 2005). Additionally, post-exercise cooling might reduce the exercise-induced thermal load prior to any ensuing (King and Duffield 2009), or repeated exercise bouts (Vaile et al. 2008; Vaile et al. 2011). Despite the use of a range of cooling techniques to reduce the thermal load during or following exercise, the literature comparing these techniques remains inconclusive, particularly in temperate environments (Castle et al. 2006; Duffield and Marino 2007).

Interestingly, in addition to convective heat loss, the effect of hydrostatic pressure during water immersion techniques may be an important aspect of the effectiveness of water immersion interventions (Park et al. 1999). The pressure applied to the body during water immersion may cause displacement of fluids from the extremities, thus increasing the central blood volume, and leading to an increased stroke volume during immersion (BondePetersen et al. 1992; Gabrielsen et al. 2002; Stocks et al. 2004). As an example, HR has been shown to decrease by $15 \%$ in water at $30^{\circ} \mathrm{C}$ (Park et al. 1999). It is proposed that hemodynamic changes are mediated through increased venous return to the thorax due to the hydrostatic pressure gradient (Ernst 1986). Moreover, a previous study (Pournot et al. 2011) comparing immersion to the iliac crest at varying temperatures found a better performance effect in $30 \mathrm{~s}$ of rowing from colder temperatures $\left(10^{\circ} \mathrm{C}\right)$ when compared with a warmer $\left(30^{\circ} \mathrm{C}\right)$ temperature. Alternatively, more practical cooling methods, such as cooling jackets, have been used to provide the physiological benefits of cooling (Brade et al. 2010; Ross et al. 2011). It is classically reported that cooling jackets display a sufficient cooling effect (Duffield and Marino 2007; Gao et al. 2011; Hunter et al. 2006; Smolander et al. 2004), which can attenuate the rise in Tcore and Tskin during subsequent running, and reduce HR for a fixed-exercise intensity in the heat (Cheung and Robinson 2004; Hunter et al. 2006; Uckert and Joch 2007; Webster et al. 2005). However, the literature directly comparing these different strategies (cold water immersion [CWI] and cooling jackets) to cool the body is sparse in temperate conditions (Gao et al. 2011; Webster et al. 2005). To the best of our knowledge, only one study compared water immersion to cooling jackets (Duffield and Marino 2007) between subsequent exercises performed in warm conditions and no report exists on the effectiveness of these methods between exercise bouts in temperate conditions. 
Within this context, the purpose of this investigation was to compare the immersion effects of CWI to the use of a cooling jacket 'Cryovest' (V), and to a passive rest group (PAS) on physiological and thermoregulatory responses to exercise-induced heat stress in a temperate environment. It was hypothesized that V (the most practical cooling method) might provide significant physiological benefits for both post-exercise recovery and ensuing exercise performance at least as important as CWI and more important than PAS.

\section{Material and methods}

\section{Subjects}

Nine well-trained male cyclists (age: $24.1 \pm 2.6 \mathrm{yr}$, height: $180.3 \pm 8.3 \mathrm{~cm}$, body mass: $79.5 \pm 14.7 \mathrm{~kg}$, sum of four skin folds: $34.5 \pm 18.5 \mathrm{~mm}$, body surface area: $2.0 \pm 0.2 \mathrm{~m}^{2}$, peak oxygen uptake: $4.2 \pm 0.7 \mathrm{~L} . \mathrm{min}^{-1}$, maximal power output: $4.7 \pm 1.2 \mathrm{~W} . \mathrm{kg}^{-1}$ ) participated in this study. All participants had no recent specific acclimation to heat or cold and usually performed 5 training sessions per week, including approximately $1 \mathrm{~h} 30 \mathrm{~min}$ of aerobic work per session. All participants were volunteers and were informed about the study protocol, the risks of tests and investigations, and their rights according to the Declaration of Helsinki. Participants gave their written informed consent andthe local Ethics Committee approved the study before its initiation.

\section{Experimental trials}

The experimental protocol was composed of four testing sessions in the laboratory, including a familiarization trial and three experimental trials, each separated by at least two days. Each testing session was performed in a climate-controlled room at $20^{\circ} \mathrm{C}$ and with a relative humidity $(\mathrm{RH})$ of $60 \%$. A repeated measures design, with participants acting as their own controls was used. Each session involved two $45 \mathrm{~min}$ constant-intensity cycling bouts at $60 \%$ of maximal aerobic power (MAP). In a randomized fashion, during each respective session subjects performed either a PAS, CWI or wore $\mathrm{aV}$ for $25 \mathrm{~min}$ between the two cycling bouts. To minimize the influence of circadian variations, all subjects arrived at the same time of day and were required to fast for at least 3 hours before the initiation of the experiment. Subjects refrained from drinking alcohol or caffeine over $48 \mathrm{~h}$ prior to testing and were allowed to drink only water during exercise.

\section{Preliminary testing}


Two days prior to the first trial, an incremental cycle ergometer test was performed to determine $\dot{\mathrm{V}} \mathrm{O}_{2 \max }$ and MAP. Power output was increased from 90 watts (W) to exhaustion with $25 \mathrm{~W}$ steps at 2 min intervals on a cycling ergometer (Excalibur, Lode, Gröningen, The Netherlands). The results of this test were used to determine the relative intensity for each participant in subsequent exercise bouts. $\dot{\mathrm{V}} \mathrm{O}_{2}$, minute ventilation $\left(\dot{\mathrm{V}}_{\mathrm{E}}\right)$, and the respiratory exchange ratio (RER) were continuously recorded with a breath-by-breath gas exchange analyzer $\left(\mathrm{K}_{4} \mathrm{~b}^{2}\right.$, COSMED, Italy), calibrated for volume and fractional gas concentrations prior to each test. HR was monitored by using an internal module of the gas analyzer and a Polar chest transmitter (Polar Electro Oy, Helsinki, Finland). Three criteria were used to determine $\dot{\mathrm{V}} \mathrm{O}_{2 \text { max }}$ : a plateau in $\dot{\mathrm{V}} \mathrm{O}_{2}$ despite an increase in power output, a RER greater than 1.1, and HR above $90 \%$ of the predicted maximal HR (Howley et al. 1995). $\dot{\mathrm{V}} \mathrm{O}_{2 \max }$ was determined from the four highest $\dot{\mathrm{V}} \mathrm{O}_{2}$ values recorded when $\dot{\mathrm{V}}{ }_{2}$ reached a plateau, whilst MAP was determined as the mean cycling power output recorded over the 2 min period equating with $\dot{\mathrm{V}} \mathrm{O}_{2 \max }$.

\section{Exercise protocol}

Prior to starting exercise, subjects remained in the temperate room at $20 \pm 1^{\circ} \mathrm{C}, 60 \pm 2 \% \mathrm{RH}$ for $30 \mathrm{~min}$ for preparation and pre-exercise measures. All testing sessions including cycling exercise, warm-up periods and recovery modalities, were performed in the same climate chamber providing the same environmental conditions (IMNSSA-IRBA, Toulon, France). Subjects completed a $15 \mathrm{~min}$ warm-up cycling protocol at 25\% MAP $(90.2 \pm 15.2 \mathrm{~W})$, followed by two $45 \mathrm{~min}$ cycling bouts at $60 \%$ MAP $(216.5 \pm 36.4 \mathrm{~W})$ separated by a $25 \mathrm{~min}$ recovery period. All cycling exercises were performed on the same cycle ergometer used for the incremental cycling exercise test.

\section{Recovery modalities}

Immediately after the first cycling bout, participants performed one of the following three recovery strategies for 25 min. 1) For the control condition (PAS), subjects remained passively seated for the entirety of the recovery period. 2) A cooling vest (V) Cryovest $^{\circledR}$ (SM Europe, La Mézière, FRANCE), composed of eight cryopacks stored at $-4^{\circ} \mathrm{C}$ until use, was worn by subjects while remaining seated. 3) Subjects were immersed to the sternum in a seated position in cool water $\left(20^{\circ} \mathrm{C}\right)(\mathrm{CWI})$. This temperature was chosen according to previous studies reporting no difference in core and skin temperatures, blood lactate concentration and heart rate, between water at 10 and $20^{\circ} \mathrm{C}$ (Kaur et al. 2008). Further, this temperature was likely better tolerated by athletes for the duration of the exposure. Each recovery intervention was performed in the climate chamber and participants were instructed not to drink during the recovery period in order to control for urine loss. 


\section{Measurements and procedures}

\section{Oxygen uptake, ventilation, heart rate and blood pressure}

During cycling exercise, $\dot{\mathrm{VO}}_{2}, \dot{\mathrm{V}}_{\mathrm{E}}$, and $\mathrm{HR}$ were continuously recorded within the 6 first minutes and the last 10minutes of each exercise bout using the same apparatus outlined for preliminary testing. Systolic Blood pressure (Sys BP) and diastolic blood pressure (Dia BP) were measured as soon as possible at the end of exercise by using an oscillometric sphygmomanometer (705 IT, Omron, Kyoto, Japan) on the left armwhile the subject was in a lying position. Measures of BP were performed before the experiment (Pre) after the end of exercise 1 (Ex1) recovery $(\mathrm{R})$ and exercise $2(\mathrm{Ex} 2)$

\section{Capillary blood metabolites}

Blood samples $(100 \mu \mathrm{L})$ were collected from the earlobe at four time points; Pre-exercise, at the end of Ex1, after $\mathrm{R}$, and after Ex2 (figure 1). Samples were analyzed to determine blood lactate (La'), serum sodium concentration $\left(\mathrm{Na}^{+}\right)$, blood $\mathrm{pH}(\mathrm{pH})$, and blood bicarbonate $\left(\mathrm{HCO}_{3}{ }^{-}\right)$concentration. Samples were collected in heparinized capillary tubes and immediately placed in the receptacle of a Cartbridge ${ }^{\circledR} \mathrm{GC} 8+$ cartridge for clinical chemistry analysis on anI-Stat ${ }^{\circledR}$ analyzer (Abbott Point of CareInc., Illinois,USA).

\section{Thermoregulatory measures}

To assess thermoregulatory responses during exercise and recovery periods, subjects ingested a thermo-sensitive capsule to measure Tcore (HQ Inc Thermo pills, Palmetto, Florida, USA), 4h prior to starting tests (Wilkinson et al. 2008). In addition, skin temperature was analyzed at 7 different points (on the head, forearm, hand, abdomen, thigh, tibia and foot) with thermistance sensors (PT100, New Jersey, USA). Tskin was calculated by assigning a coefficient to each of the measurements, proportional to the area occupied by each specific region compared to the total body surface area (Hardy and Dubois 1938; Lenhardt and Sessler 2006) (equation 1). The mean body temperature (Tbody) was estimated according to the methods described by Schmidt and Bruck (1981) (equation 2).

(1) Tskin $\left({ }^{\circ} \mathrm{C}\right)=0.07 \times\left(\mathrm{T}_{\text {head }}\right)+0.14\left(\mathrm{~T}_{\text {forearm }}\right)+0.05\left(\mathrm{~T}_{\text {hand }}\right)+0.35\left(\mathrm{~T}_{\text {abdomen }}\right)+0.19\left(\mathrm{~T}_{\text {thigh }}\right)+0.13\left(\mathrm{~T}_{\text {tibia }}\right)+$

$$
0.07\left(\mathrm{~T}_{\text {foot }}\right)
$$

(2) Tbody $\left({ }^{\circ} \mathrm{C}\right)=0.87$ Tcore +0.13 Tskin 


\section{Hydration status and sweat secretion}

Before starting the experiment, participants provided a urine sample to assess the specific gravity of urine as an indicator of hydration status. This test was performed using dip-test strips (Sallamander Concepts (Pty), Pretoria, South Africa). Specific gravity was determined by matching the strip color with a color chart outlining specific gravity. Furthermore, body mass loss (BML) was calculated from measures of body mass before (Pre) and at the completion of Ex2 using a digital platform scale (model ED3300; Sauter Multi-Range, Ebingen, West Germany) as a representative of sweat mass lost. Subjects were authorized to drink $600 \mathrm{ml}$ of water within the 45 minutes of each exercise when they were not wearing the mask of the gas analyzer.The total amount ingested was accounted for in body mass calculation by adding the estimated mass of fluid consumed to the difference in pre to postexercise change in body mass. .

\section{Statistical analyses}

Statistical analysis was performed using Statistica 7 for Windows (StatSoft, Inc. Tulsa, Oklahoma, USA). Differences in the measured variables among conditions and trials were analyzed with a two-way ANOVA for repeated measures (recovery modality $\times$ time), using recovery modality as the between-subjects factor and time as the within-subjects factor. When there was a significant main effect or interaction, differences were located using Newman-Keuls post hoc test or, for data that were not normally distributed, a Wilcoxon's signed rank test. Significance was set at $\mathrm{P}<0.05$. All values are expressed as means \pm standard deviation.

\section{Results}

\section{$1^{\text {st }}$ period of exercise}

Pre-exercise body mass was not different between conditions $(79.48 \pm 14.70 \mathrm{~kg} ; 79.48 \pm 14.65 \mathrm{~kg} ; 79.48 \pm 14.70 \mathrm{~kg}$, respectively for PAS, V and CWI). On arrival, all subjects presented a hydrated state between $1.010-1.020$ g.mL $\mathrm{m}^{-1}$. The first exercise bout resulted in significant increases in $\dot{\mathrm{VO}}_{2}, \dot{\mathrm{V}}_{\mathrm{E}}, \mathrm{BP}, \mathrm{HR}, \mathrm{Tbody}$, Tcore and Tskin, $\mathrm{La}^{-}$and $\mathrm{Na}^{+}$(table 1, figure 2; $\mathrm{P}<0.05$ ). Conversely, both $\mathrm{HCO}_{3}{ }^{-}$and blood $\mathrm{pH}$ were reduced by the exercise bout in all conditions (table 1; $\mathrm{P}<0.05$ ). However, there were no significant between-condition differences in any physiological variables at the end of the first $45 \mathrm{~min}$ exercise bout (table $1 ; \mathrm{P}>0.05$ ).

\section{Recovery period}


Following the 25 min recovery intervention, $\dot{\mathrm{V}}_{2}, \dot{\mathrm{V}}_{\mathrm{E}}$, blood pressure, $\mathrm{HR}, \mathrm{La}^{-}$and $\mathrm{Na}^{+}$were significantly reduced compared to the end of the first 45 min exercise bout $(\mathrm{P}<0.05)$, without differences between conditions (table 1; $\mathrm{P}>0.05)$. Conversely, $\mathrm{HCO}_{3}{ }^{-}$was increased following the $25 \mathrm{~min}$ recovery $(\mathrm{P}<0.05)$, again without differences between conditions ( $\mathrm{P}>0.05)$. Tbody continued to increase in PAS condition, whereas it did not change with the use of $\mathrm{V}$ and was significantly decreased with CWI (table 1; $\mathrm{P}<0.05$ ). More specifically, Tskin was unchanged with the use of $\mathrm{V}$, while reduced with $\mathrm{CWI}$, and increased with PAS $(\mathrm{P}<0.05)$. Furthermore, Tcore was unchanged with $\mathrm{V}$ and $\mathrm{CWI}(\mathrm{P}>0.05)$ and continued to increase with PAS (figure 2; $\mathrm{P}<0.05$ ).

\section{$2^{\text {nd }}$ period of exercise}

Tskin and Tcore were significantly lower $(\mathrm{p}<0.05)$ after Ex2 in CWI and V conditions compared to PAS, while lower values $(\mathrm{p}<0.05)$ were observed with CWI compared to V (figure 2). Although final end-Ex2 values did not differ between respective conditions $(\mathrm{P}>0.05)$, the relative increase from end-Ex1 to end-Ex2 in HR, $\dot{\mathrm{V}}_{\mathrm{E}}$ and $\dot{\mathrm{V}} \mathrm{O}_{2}$ were significantly lower in the $\mathrm{V}$ condition compared to CWI and PAS (table 2; $<<0.05$ ). Similarly, despite no differences in final absolute values $(\mathrm{P}>0.05)$, Sys $\mathrm{BP}$ increased in greater proportion in $\mathrm{V}$ condition $(+19.4 \pm 7.6 \mathrm{mmHg})$ compared to CWI $(+3.9 \pm 6.5 \mathrm{mmHg})$ from Ex1 to Ex2 (table 2; $\mathrm{P}<0.05$ ), whilst $\mathrm{Na}^{+}$ significantly increased after Ex2 only in CWI condition (table 1; $\mathrm{P}<0.05$ ). The increase in La after Ex2 was significantly lower (table 2; $\mathrm{P}<0.05$ ) in CWI condition when compared to $\mathrm{V}$ and PAS $\left(+1.0 \pm 0.3 \mathrm{mmol} . \mathrm{L}^{-1}\right.$; $+2.6 \pm 0.6$ mmol. $\mathrm{L}^{-1} ;+3.3 \pm 0.4$ mmol. $\mathrm{L}^{-1}$, respectively) while values were lower in CWI than $\mathrm{V}$ (table $1 ; \mathrm{P}<0.05$ ). In addition, $\mathrm{HCO}_{3}{ }^{-}$significantly decreased after Ex2 in similar proportions in all conditions, and blood $\mathrm{pH}$ significantly decreased only in CWI condition (table $1 ; \mathrm{P}<0.05$ ). BML values are presented in figure 3 , with the smallest changes recorded in CWI condition compared to V and PAS $(\mathrm{P}<0.05)$.

\section{Discussion}

The aim of this study was to compare the effects of different recovery modalities (CWI $v s$.V vs. PAS) on ensuing physiological and thermoregulatory responses to exercise-induced heat stress in a temperate environment. The use of $\mathrm{V}$ had beneficial effects on subsequent cycling exercise by attenuating Tskin and Tcore and blunting the rise from end-Ex1 to end-Ex2 in $\mathrm{HR}, \dot{\mathrm{VO}}_{2}, \dot{\mathrm{V}}_{\mathrm{E}}$, whereas $\mathrm{CWI}$ was beneficial in lowering La', Tcore, Tskin and BML during the subsequent bout. Therefore, both Vand CWI cooling strategies were effective in enhancing post-exercise recovery and attenuating thermoregulatory and physiological alterations during a subsequent submaximal exercise bout in temperate environments. 
Exercised-induced hyperthermia is reported to be an important factor contributing to premature termination or reduction of endurance exercise performance (Cheuvront et al. 2010; Nybo et al. 2001; Webster et al. 2005). Indeed, the main purpose of any cooling intervention is to limit the exercise-induced increase in skin and core temperatures. During Ex1, Tbody for all subjects reached $38.6 \pm 0.1{ }^{\circ} \mathrm{C}$, similar to a recent study conducted in warm conditions $\left(30^{\circ} \mathrm{C}, 40 \% \mathrm{RH}\right)$ after a 30 min cycling exercise at $60 \%$ MAP $\left(38.5 \pm 0.2^{\circ} \mathrm{C}\right)$, (Luomala et al. 2012). Both CWI and V prevented the continued rise in Tbody following $\mathrm{R}$ ( $\mathrm{P}<0.05$; table 1), with Tbody returning to post Ex1 values with the use of V, and to basal values with CWI (table 1). Similarly, Vaile et al. (2008) reported that water immersion at $20^{\circ} \mathrm{C}$ for $15 \mathrm{~min}$ between two exercises significantly decreased Tbody $\left(36.10 \pm 0.20^{\circ} \mathrm{C} v s .36 .25 \pm 0.69^{\circ} \mathrm{C}\right.$ in the present study) and was effective in maintaining subsequent high intensity cycling performance. It can be suggested that changes in blood distribution occur during water immersion, shifting away from the periphery and toward the core (Marsh and Sleivert 1999) and are effective in reducing thermal strain (Vaile et al. 2008). Although Tskin was significantly increased with PAS (+8\%), returned to basal values with the use of $\mathrm{V}(+0.25 \%)$, and reduced under basal values with CWI $(-31 \%)$, Tcore remained elevated above basal values in all conditions (figure 2). However, Tcore following the recovery intervention increased only in PAS when compared to Ex1, confirming a beneficial thermoregulatory effect of the two cooling methods. Thus, it seems that CWI was the most effective strategy to limit and even reduce body temperature after exercise. Such a finding may be explained by the higher conductive and convective power of water compared to $\mathrm{V}$, and the greater body surface exchange in water immersion. Although CWI and V were effective in reducing the rise in Tbody after the first exercise bout, these methods had no effect on the recovery of any other physiological values recorded (table 1). The results from the present study confirm that post-exercise cooling can reduce the exercise-induced thermal load in a temperate environment.

While cooling strategies following Ex1 were effective in reducing the rise in body temperature, without marked effects on other physiological variables, further beneficial effects of cooling strategies were evident during subsequent exercise. Indeed, results of this study indicate lower increases in Tbody after Ex2 with the use of CWI strategy compared to PAS (table $1 ; \mathrm{P}<0.05$ ). When comparing the change from end-Ex1 to end-Ex2, the respective cooling interventions resulted in a lower relative change in physiological variables such as $\dot{\mathrm{V}} \mathrm{O}_{2}$, $\mathrm{HR}, \dot{\mathrm{V}}_{\mathrm{E}}$, and $\mathrm{La}^{-}$for $\mathrm{V}$ and a greater decrease of $\mathrm{La}^{-}$with $\mathrm{CWI}$ (table 2; $\mathrm{P}<0.05$ ), despite no difference in final absolute values. The most common pre-cooling strategies used in a sporting context are water immersion and ice application through cooling jackets, towels or ice packs(Duffield 2008; Peiffer et al. 2009). Similarly to postcooling strategies, the main purpose of pre-cooling is to limit the rise in body temperature and associated physiological alterations during the subsequent exercise, and thus enhance exercise tolerance. As expected, in our 
study Tskin and Tcore recorded during Ex2 were significantly lowered after $\mathrm{V}$ and CWI interventions when compared to PAS. Moreover, similar to previous studies, whole-body cooling with CWI resulted in a lower Tcore and Tskin during the subsequent exercise compared to partial body cooling (Daanen et al. 2006; White et al. 2003). Finally, both interventions reduced Tskin, but the greater decrease was obtained with CWI, by exposing approximately twice as much skin surface area than $\mathrm{V}$, resulting in agreater afferent stimulation of water on the entire body (Castle et al. 2006). Reduced HR with V and CWI, have been demonstrated in previous cooling investigations (Kenny et al. 2011; Uckert and Joch 2007; Yeargin et al. 2006). Hornery et al. (2005)also observed a trend towards lower $\dot{\mathrm{VO}} 2$ and $\mathrm{HR}$ values following $\mathrm{V}$ during a constant cycling exercise at $75 \% \quad \dot{\mathrm{V}} 2$ max in a similar environment $\left(21^{\circ} \mathrm{C}\right.$ vs $20^{\circ} \mathrm{C}$ in the present study). Lower relative changes in exercise-induced responses ie Ex1 to Ex2 for sub-maximal $\mathrm{HR}$ and $\dot{\mathrm{VO}}_{2}$ values after $\mathrm{V}$ exposition may suggest a cold-related peripheral vasoconstriction, and a greater central blood volume; often reported to enhance $\mathrm{O}_{2}$ perfusion to active muscles, removal of waste substances and assist exercise tolerance (Hessemer et al. 1984; Hornery et al. 2005; Park et al. 1999; Vaile et al. 2008). However, the sudden and greater change in Tskin when entering water probably caused more severe vasoconstriction than $\mathrm{V}$, along with potential increases in catecholamine release (Kozyreva et al. 1999) and BP (Janský et al. 1996). Whilst speculative, based on the lowered Tskin, it can be hypothesized that a greater vasoconstriction may be present following CWI (figure 2), in turn resulting in the observed lower relative change between Ex1 and Ex2 for Sys BP(Mack et al. 1998), HR, $\dot{V O}_{2}, \dot{\mathrm{V}}_{\mathrm{E}}$ and evaporative heat loss, when compared to V(Hayashi et al. 2011); despite similar final absolute values.

Additionally, the increase in indicators of metabolic acidosis $\left(\mathrm{pH}, \mathrm{La}^{-}\right)$and dehydration (BML) were significantly reduced after Ex2, particularly in comparison to Ex1, by using larger cooling strategies CWI for La' and BML (table 2, figure 3). An increase in central blood volume may provide greater blood availability, and increase the clearance of metabolic by-products (Marsh and Sleivert 1999) during submaximal exercise (Hessemer et al. 1984). Our results differ from Duffield et al. (2010) whose subjects immerged only the lower limbs for $20 \mathrm{~min}$ at $14^{\circ} \mathrm{C}$, but are consistent with those reported by Kaur et al. (2008)who used a CWI protocol similar to ours (immersion of the whole body for $20 \mathrm{~min}$ at $16^{\circ} \mathrm{C}$ ). Therefore, it seems that whole body immersion would be necessary to induce significant physiological changes compared to partial body immersion. Indeed, the central blood volume expansion is dependent upon immersion of the torso (Johansen et al. 1997). In the present study, the greater decrease in temperature observed with CWI compared to V may have led to the larger drop in $\mathrm{La}^{-}$during Ex2. In contrast, our results do not indicate a dose-response for pre-cooling methods, as the largest stimulus did not result in greater physiological perturbations. These results may suggest that cooling strategy 
effectiveness are dependent on the type of exercise and environmental conditions; with CWI most appropriate when an aggressive reduction in thermal load is required, such as in a warm environment; whereas V may be recommended in temperate conditions that induce lower endogenous thermal loads. Moreover, given logistical concerns over the field-based use of CWI, it is noteworthy that within the constraints of applied settings, cold interventions such as the $\mathrm{V}$ may still provide sufficient reductions in the thermoregulatory and physiological strain when subsequent exercises have to be performed in temperate environments.

Finally, the greater decrease in Tskin following CWI may also explain the lower sweat loss recorded after Ex2 (table 2 and figure 3). The lower sweat loss assessed through BML in CWI may be the result of a better convection /conduction mechanism and less reliance on evaporative heat loss. Moreover, the lower Tskin at the onset of Ex2 could also reduce skin blood flow, traditionally associated with decreased sweat rates (Nishiyasu et al. 1992). Similarly, Wilson et al. (2002) reported a significant decrease in sweat rate during submaximal exercise $\left(60 \% \dot{\mathrm{V}} \mathrm{O}_{2 \max }\right)$ performed in a temperate environment $\left(21^{\circ} \mathrm{C}\right)$ after a water immersion to the iliac crest $\left(18^{\circ} \mathrm{C}\right)$. In contrast, Bogerd et al. (2010) reported no effect of wearing a cooling jacket on sweat rate during exercise in a climatic chamber $\left(29.3^{\circ} \mathrm{C}, \mathrm{RH}: 80 \%\right)$. Further, in a previous study conducted under similar ambient temperature to the current study $\left(21.3^{\circ} \mathrm{C}\right.$, RH: $\left.33 \%\right)$, total fluid loss did not differ significantly between the cooling jacket $(1479 \pm 532 \mathrm{ml})$ and control $(1512 \pm 496 \mathrm{ml})$ interventions. The cumulative effects of hydrostatic pressure and cold-related vasoconstriction during immersion could increase diuresis and blood transcapillary reabsorption (movement of fluid from the interstitial to the intravascular space), responsible for the increase in $\mathrm{Na}^{+}$blood concentration and the decrease in pH after Ex2 (Stocks et al. 2004). However, similarly to previous studies no effect of cooling interventions were evident for $\mathrm{HCO}_{3}{ }^{-}$(Booth et al. 2001; King and Duffield 2009; Quod et al. 2008), suggesting no effect on blood alkalinity.

\section{Conclusion}

The results of this study indicate that cooling strategies result in a faster reduction in thermoregulatory strain following exercise in temperate conditions. Furthermore, these post-exercise cooling interventions enhanced thermoregulatory adaptations (Tbody, Tcore and Tskin) and physiological changes (rise in HR, $\left.\dot{\mathrm{VO}}_{2}, \dot{\mathrm{V}}_{\mathrm{E}}, \mathrm{La}^{-}\right)$recorded at the end of an ensuing exercise bout in the same temperate conditions. Comparison between cooling methods suggests CWI to have a larger effect on reducing thermoregulatory load, and in accordance with previous studies, a greater heat loss would be obtained with whole-body cooling than partialbody cooling; likely related to the larger skin surface area exposed to cooling. However, although the V cooling 
method had a lower cooling effect on the body temperature, greater benefits on physiological load (change in HR, $\dot{\mathrm{VO}}_{2}$ and $\dot{\mathrm{V}}_{\mathrm{E}}$ ) in the early stage of a subsequent exercise were observed compared with CWI. According to these results, post-exercise cooling with either CWI or V provides thermoregulatory benefits for ensuing exercise in temperate environments. Given the logistical demands of CWI in the field, the use of V in temperate environments may be an appropriate intervention to assist post-exercise thermal recovery for ensuing exercise bouts even when the exogenous thermal load is not high.

\section{Acknowledgments}

We would like to greatly acknowledge the cyclists, Dr. Olivier Castagna, Anne-virginie Desruelle and Bruno Schmid for their active participation in the exercise protocol.

\section{References}

Arngrimsson, S.A., Petitt, D.S., Stueck, M.G., Jorgensen, D.K. and Cureton, K.J. 2004. Cooling vest worn during active warm-up improves 5-km run performance in the heat. J Appl Physiol. 96: 1867-74

Bogerd, N., Perret, C., Bogerd, C.P., Rossi, R.M. and Daanen, H.A. 2010. The effect of pre-cooling intensity on cooling efficiency and exercise performance. J Sports Sci. 28: 771-9

Bonde-Petersen, F., Schultz-Pedersen, L. and Dragsted, N. 1992. Peripheral and central blood flow in man during cold, thermoneutral, and hot water immersion. Aviat Space Environ Med. 63: 346-50

Booth, J., Wilsmore, B.R., Macdonald, A.D., Zeyl, A., McGhee, S., Calvert, D., Marino, F.E., Storlien, L.H. and Taylor, N.A. 2001. Whole-body pre-cooling does not alter human muscle metabolism during submaximal exercise in the heat. Eur J Appl Physiol. 84: 587-90

Brade, C., Dawson, B., Wallman, K. and Polglaze, T. 2010. Postexercise cooling rates in 2 cooling jackets. J Athl Train. 45: 164-9

Buchheit, M., Peiffer, J.J., Abbiss, C.R. and Laursen, P.B. 2009. Effect of cold water immersion on postexercise parasympathetic reactivation. Am J Physiol Heart Circ Physiol. 296: H421-7

Castle, P.C., Macdonald, A.L., Philp, A., Webborn, A., Watt, P.W. and Maxwell, N.S. 2006. Precooling leg muscle improves intermittent sprint exercise performance in hot, humid conditions. J Appl Physiol. 100: $1377-84$

Cheung, S. and Robinson, A. 2004. The influence of upper-body pre-cooling on repeated sprint performance in moderate ambient temperatures. J Sports Sci. 22: 605-12

Cheuvront, S.N., Kenefick, R.W., Montain, S.J. and Sawka, M.N. 2010. Mechanisms of aerobic performance impairment with heat stress and dehydration. J Appl Physiol. 109: 1989-95

Daanen, H.A., van Es, E.M. and de Graaf, J.L. 2006. Heat strain and gross efficiency during endurance exercise after lower, upper, or whole body precooling in the heat. Int J Sports Med. 27: 379-88

Duffield, R. 2008. Cooling interventions for the protection and recovery of exercise performance from exerciseinduced heat stress. Med Sport Sci. 53: 89-103

Duffield, R., Dawson, B., Bishop, D., Fitzsimons, M. and Lawrence, S. 2003. Effect of wearing an ice cooling jacket on repeat sprint performance in warm/humid conditions. Br J Sports Med. 37: 164-9

Duffield, R., Green, R., Castle, P. and Maxwell, N. 2010. Precooling can prevent the reduction of self-paced exercise intensity in the heat. Med Sci Sports Exerc. 42: 577-84

Duffield, R. and Marino, F.E. 2007. Effects of pre-cooling procedures on intermittent-sprint exercise performance in warm conditions. Eur J Appl Physiol. 100: 727-35

Duffield, R., Steinbacher, G. and Fairchild, T.J. 2009. The use of mixed-method, part-body pre-cooling procedures for team-sport athletes training in the heat. J Strength Cond Res. 23: 2524-32

Ernst, E. 1986. Observations on the effects of immersion in Bath spa water. Br Med J (Clin Res Ed). 292: 343

Farhi, L.E. and Linnarsson, D. 1977. Cardiopulmonary readjustments during graded immersion in water at 35 degrees C. Respir Physiol. 30: 35-50

Gabrielsen, A., Pump, B., Bie, P., Christensen, N.J., Warberg, J. and Norsk, P. 2002. Atrial distension, haemodilution, and acute control of renin release during water immersion in humans. Acta Physiol Scand. 174: 91-9 
Galloway, S.D. and Maughan, R.J. 1997. Effects of ambient temperature on the capacity to perform prolonged cycle exercise in man. Med Sci Sports Exerc. 29: 1240-9

Gao, C., Kuklane, K. and Holmer, I. 2011. Cooling vests with phase change materials: the effects of melting temperature on heat strain alleviation in an extremely hot environment. Eur J Appl Physiol. 111: 120716

Hardy, J.D. and Dubois, E.F. 1938. Basal metabolism, radiation, convection, and evaporation at temperate form $22^{\circ}$ to $35^{\circ} \mathrm{C}$. J Nutr. 15: $477-492$

Hasegawa, H., Takatori, T., Komura, T. and Yamasaki, M. 2005. Wearing a cooling jacket during exercise reduces thermal strain and improves endurance exercise performance in a warm environment. J Strength Cond Res. 19: 122-8

Hayashi, K., Honda, Y., Miyakawa, N., Fujii, N., Ichinose, M., Koga, S., Kondo, N. and Nishiyasu, T. 2011. Effect of $\mathrm{CO}$ on the ventilatory sensitivity to rising body temperature during exercise. J Appl Physiol. 110: $1334-41$

Hessemer, V., Langusch, D., Bruck, L.K., Bodeker, R.H. and Breidenbach, T. 1984. Effect of slightly lowered body temperatures on endurance performance in humans. J Appl Physiol. 57: 1731-7

Hornery, D.J., Papalia, S., Mujika, I. and Hahn, A. 2005. Physiological and performance benefits of halftime cooling. J Sci Med Sport. 8: 15-25

Howley, E.T., Bassett, D.R., Jr. and Welch, H.G. 1995. Criteria for maximal oxygen uptake: review and commentary. Med Sci Sports Exerc. 27: 1292-301

Hunter, I., Hopkins, J.T. and Casa, D.J. 2006. Warming up with an ice vest: core body temperature before and after cross-country racing. J Athl Train. 41: 371-4

Janský, L., Janáková, H., B, U., Srámek, P., Hosek, V., Heller, J. and Parízková, J. 1996. Changes in thermal homeostasis in humans due to repeated cold water immersions. Pflugers Arch. 432(3): 368-72.

Johansen, L.B., Jensen, T.U., Pump, B. and Norsk, P. 1997. Contribution of abdomen and legs to central blood volume expansion in humans during immersion. J Appl Physiol. 83: 695-9

Kaur, P., Sarika and Jaspal Singh, S. 2008. Effect of precooling and prewarming on endurance performance and blood lactate concentration. Sports Med J. 4 (16):

Kenny, G.P., Reardon, F.D., Giesbrecht, G.G., Jette, M. and Thoden, J.S. 1997. The effect of ambient temperature and exercise intensity on post-exercise thermal homeostasis. Eur J Appl Physiol Occup Physiol. 76: 109-15

Kenny, G.P., Schissler, A.R., Stapleton, J., Piamonte, M., Binder, K., Lynn, A., Lan, C.Q. and Hardcastle, S.G. 2011. Ice Cooling Vest on Tolerance for Exercise under Uncompensable Heat Stress. J Occup Environ Hyg. 8: 484-91

King, M. and Duffield, R. 2009. The effects of recovery interventions on consecutive days of intermittent sprint exercise. J Strength Cond Res. 23: 1795-802

Kozyreva, T.V., Tkachenko, E.Y., Kozaruk, V.P., Latysheva, T.V. and Gilinsky, M.A. 1999. Effects of slow and rapid cooling on catecholamine concentration in arterial plasma and the skin. Am J Physiol. 276: R1668-72

Kruk, B., Pekkarinen, H., Harri, M., Manninen, K. and Hanninen, O. 1990a. Thermoregulatory responses to exercise at low ambient temperature performed after precooling or preheating procedures. Eur J Appl Physiol Occup Physiol. 59: 416-20

Kruk, B., Szczypaczewska, M., Opaszowski, B., Kaciuba-Uscilko, H. and Nazar, K. 1990b. Thermoregulatory and metabolic responses to repeated bouts of prolonged cycle-ergometer exercise in man. Acta Physiol Pol. 41: 22-31

Lenhardt, R. and Sessler, D.I. 2006. Estimation of mean body temperature from mean skin and core temperature. Anesthesiology. 105: 1117-21

Lundgren, C.E. 1984. Respiratory function during simulated wet dives. Undersea Biomed Res. 11: 139-47

Luomala, M.J., Oksa, J., Salmi, J.A., Linnamo, V., Holmér, I., Smolander, J. and Dugué, B. 2012. Adding a cooling vest during cycling improves performance in warm and humid conditions. Journal of Thermal Biology. 37: 47-55

Mack, G.W., Yang, R., Hargens, A.R., Nagashima, K. and Haskell, A. 1998. Influence of hydrostatic pressure gradients on regulation of plasma volume after exercise. J Appl Physiol. 85: 667-75

Marsh, D. and Sleivert, G. 1999. Effect of precooling on high intensity cycling performance. Br J Sports Med. 33: 393-7

Nishiyasu, T., Shi, X., Gillen, C.M., Mack, G.W. and Nadel, E.R. 1992. Comparison of the forearm and calf blood flow response to thermal stress during dynamic exercise. Med Sci Sports Exerc. 24: 213-7

Nybo, L., Jensen, T., Nielsen, B. and Gonzalez-Alonso, J. 2001. Effects of marked hyperthermia with and without dehydration on $\mathrm{VO}(2)$ kinetics during intense exercise. J Appl Physiol. 90: 1057-64

Park, K.S., Choi, J.K. and Park, Y.S. 1999. Cardiovascular regulation during water immersion. Appl Human Sci. 18: 233-41 
Peiffer, J.J., Abbiss, C.R., Nosaka, K., Peake, J.M. and Laursen, P.B. 2009. Effect of cold water immersion after exercise in the heat on muscle function, body temperatures, and vessel diameter. J Sci Med Sport. 12: 91-6

Pournot, H., Bieuzen, F., Duffield, R., Lepretre, P., Cozzolino, C. and Hausswirth, C. 2011. Short term effects of various water immersions on recovery from exhaustive intermittent exercise. Eur J Appl Physiol. 111: $1287-1295$

Quod, M.J., Martin, D.T., Laursen, P.B., Gardner, A.S., Halson, S.L., Marino, F.E., Tate, M.P., Mainwaring, D.E., Gore, C.J. and Hahn, A.G. 2008. Practical precooling: effect on cycling time trial performance in warm conditions. J Sports Sci. 26: 1477-87

Ronsen, O., Haugen, O., Hallen, J. and Bahr, R. 2004. Residual effects of prior exercise and recovery on subsequent exercise-induced metabolic responses. Eur J Appl Physiol. 92: 498-507

Ross, M.L., Garvican, L.A., Jeacocke, N.A., Laursen, P.B., Abbiss, C.R., Martin, D.T. and Burke, L.M. 2011. Novel precooling strategy enhances time trial cycling in the heat. Med Sci Sports Exerc. 43: 123-33

Sawka, M.N., Cheuvront, S.N. and Kenefick, R.W. 2011. High Skin Temperature and Hypohydration Impairs Aerobic Performance. Exp Physiol. In press:

Sawka, M.N., Knowlton, R.G. and Critz, J.B. 1979. Thermal and circulatory responses to repeated bouts of prolonged running. Med Sci Sports. 11: 177-80

Schmidt, V. and Bruck, K. 1981. Effect of a precooling maneuver on body temperature and exercise performance. J Appl Physiol. 50: 772-8

Siegel, R., Mate, J., Brearley, M.B., Watson, G., Nosaka, K. and Laursen, P.B. 2010. Ice slurry ingestion increases core temperature capacity and running time in the heat. Med Sci Sports Exerc. 42: 717-25

Siegel, R., Mate, J., Watson, G., Nosaka, K. and Laursen, P.B. 2012. Pre-cooling with ice slurry ingestion leads to similar run times to exhaustion in the heat as cold water immersion. J Sports Sci. 30: 155-65

Sleivert, G.G., Cotter, J.D., Roberts, W.S. and Febbraio, M.A. 2001. The influence of whole-body vs. torso precooling on physiological strain and performance of high-intensity exercise in the heat. Comp Biochem Physiol A Mol Integr Physiol. 128: 657-66

Smolander, J., Kuklane, K., Gavhed, D., Nilsson, H. and Holmer, I. 2004. Effectiveness of a light-weight icevest for body cooling while wearing fire fighter's protective clothing in the heat. Int J Occup Saf Ergon. 10: $111-7$

Stocks, J.M., Patterson, M.J., Hyde, D.E., Jenkins, A.B., Mittleman, K.D. and Taylor, N.A. 2004. Effects of immersion water temperature on whole-body fluid distribution in humans. Acta Physiol Scand. 182: 310

Tatterson, A.J., Hahn, A.G., Martin, D.T. and Febbraio, M.A. 2000. Effects of heat stress on physiological responses and exercise performance in elite cyclists. J Sci Med Sport. 3: 186-93

Tikuisis, P., Jacobs, I., Moroz, D., Vallerand, A.L. and Martineau, L. 2000. Comparison of thermoregulatory responses between men and women immersed in cold water. J Appl Physiol. 89: 1403-11

Uckert, S. and Joch, W. 2007. Effects of warm-up and precooling on endurance performance in the heat. $\mathrm{Br} \mathrm{J}$ Sports Med. 41: 380-4

Vaile, J., Halson, S., Gill, N. and Dawson, B. 2008. Effect of cold water immersion on repeat cycling performance and thermoregulation in the heat. J Sports Sci. 26: 431-40

Vaile, J., O'Hagan, C., Stefanovic, B., Walker, M., Gill, N. and Askew, C.D. 2011. Effect of cold water immersion on repeated cycling performance and limb blood flow. Br J Sports Med. 45: 825-9

Walsh, N. and Whitham, M. 2006. Exercising in environmental extremes : a greater threat to immune function? Sports Med. 36(11): 941-76

Webster, J., Holland, E.J., Sleivert, G., Laing, R.M. and Niven, B.E. 2005. A light-weight cooling vest enhances performance of athletes in the heat. Ergonomics. 48: 821-37

White, A.T., Davis, S.L. and Wilson, T.E. 2003. Metabolic, thermoregulatory, and perceptual responses during exercise after lower vs. whole body precooling. J Appl Physiol. 94: 1039-44

Wilcock, I.M., Cronin, J.B. and Hing, W.A. 2006. Physiological response to water immersion: a method for sport recovery? Sports Med. 36: 747-65

Wilkinson, D.M., Carter, J.M., Richmond, V.L., Blacker, S.D. and Rayson, M.P. 2008. The effect of cool water ingestion on gastrointestinal pill temperature. Med Sci Sports Exerc. 40: 523-8

Wilson, T.E., Johnson, S.C., Petajan, J.H., Davis, S.L., Gappmaier, E., Luetkemeier, M.J. and White, A.T. 2002. Thermal regulatory responses to submaximal cycling following lower-body cooling in humans. Eur J Appl Physiol. 88: 67-75

Yeargin, S.W., Casa, D.J., McClung, J.M., Knight, J.C., Healey, J.C., Goss, P.J., Harvard, W.R. and Hipp, G.R. 2006. Body cooling between two bouts of exercise in the heat enhances subsequent performance. J Strength Cond Res. 20: 383-9 


\section{TABLES}

Table 1: Mean \pm SD data for physiological variables at rest (Pre), following exercise bout 1 (Ex1) recovery (R), and exercise bout 2 (Ex2)

\begin{tabular}{|c|c|c|c|c|c|}
\hline & & PRE & EX1 & $\mathbf{R}$ & EX2 \\
\hline \multirow[t]{3}{*}{ HR (bpm) } & PAS & $69.3 \pm 14.1$ & $154.5 \pm 14.37 *$ & $74.2 \pm 14.1 \dagger$ & $164.5 \pm 14.4 \dagger$ \\
\hline & $\mathrm{V}$ & $70.2 \pm 14.7$ & $155.1 \pm 13.97 *$ & $75.2 \pm 14.6 \dagger$ & $157.1 \pm 14.0 \dagger$ \\
\hline & CWI & $70.7 \pm 13.4$ & $155.2 \pm 14.5 *$ & $75.7 \pm 13.5 \dagger$ & $165.2 \pm 14.5 \dagger$ \\
\hline \multirow[t]{3}{*}{ Sys BP (mmHg) } & PAS & $130.0 \pm 15.0$ & $186.6 \pm 19.5 *$ & $130.0 \pm 15.0 \dagger$ & $197.7 \pm 15.6$ \\
\hline & $\mathrm{V}$ & $128.8 \pm 11.6$ & $186.1 \pm 18.1 *$ & $128.8 \pm 11.6 \dagger$ & $205.5 \pm 21.2 \dagger$ \\
\hline & CWI & $127.7 \pm 13.0$ & $187.2 \pm 15.0 *$ & $127.7 \pm 13.0 \dagger$ & $191.1 \pm 17.6$ \\
\hline \multirow[t]{3}{*}{ Dia BP (mmHg) } & PAS & $80.0 \pm 12.2$ & $90.0 \pm 4.3 *$ & $80.0 \pm 12.2 \dagger$ & $94.4 \pm 8.8$ \\
\hline & $\mathrm{V}$ & $80.0 \pm 11.1$ & $89.4 \pm 3.9 *$ & $80.0 \pm 11.1 \dagger$ & $96.1 \pm 10.5$ \\
\hline & CWI & $80.0 \pm 12.2$ & $91.11 \pm 5.4 *$ & $83.8 \pm 12.1 \dagger$ & $96.6 \pm 10.0$ \\
\hline \multirow[t]{3}{*}{$\operatorname{Tbody}\left({ }^{\circ} \mathrm{C}\right)$} & PAS & $36.3 \pm 0.3$ & $37.8 \pm 0.4 *$ & $38.6 \pm 1.2 * \dagger+$ & $39.3 \pm 0.8^{* \dagger t}$ \\
\hline & V & $36.3 \pm 0.3$ & $38.0 \pm 0.4 *$ & $38.1 \pm 0.9 * t$ & $38.6 \pm 0.8^{* \dagger}$ \\
\hline & CWI & $36.2 \pm 0.3$ & $37.9 \pm 0.4 *$ & $36.3 \pm 0.7 \dagger$ & $38.0 \pm 0.4^{*}$ \\
\hline \multirow[t]{3}{*}{$\dot{\mathrm{V}} \mathrm{O}_{2}\left(\mathrm{~L} \cdot \mathrm{min}^{-1}\right)$} & PAS & $0.40 \pm 0.08$ & $2.50 \pm 0.41 *$ & $0.50 \pm 0.08 \dagger$ & $3.12 \pm 0.40 \dagger$ \\
\hline & V & $0.40 \pm 0.08$ & $2.52 \pm 0.40 *$ & $0.50 \pm 0.08 \dagger$ & $2.91 \pm 0.40 \dagger$ \\
\hline & CWI & $0.40 \pm 0.08$ & $2.49 \pm 0.37 *$ & $0.50 \pm 0.08 \dagger$ & $3.12 \pm 0.41 \dagger$ \\
\hline \multirow{3}{*}{$\dot{\mathrm{V}}_{\mathrm{E}}\left(\mathrm{L} \cdot \mathrm{min}^{-1}\right)$} & PAS & $11.8 \pm 2.2$ & $57.2 \pm 9.05 *$ & $14.0 \pm 2.1 \dagger$ & $67.2 \pm 9.0 \dagger$ \\
\hline & $\mathrm{V}$ & $12.0 \pm 2.5$ & $58.2 \pm 8.31 *$ & $14.2 \pm 1.8 \dagger$ & $66.2 \pm 8.2 \dagger$ \\
\hline & CWI & $11.4 \pm 2.8$ & $57.2 \pm 8.09 *$ & $14.6 \pm 2.7 \dagger$ & $67.2 \pm 8.0 \dagger$ \\
\hline \multirow[t]{3}{*}{$\mathrm{La}^{-}\left(\mathrm{mmol} \cdot \mathrm{L}^{-1}\right)$} & PAS & $0.98 \pm 0.33$ & $4.27 \pm 0.67 *$ & $2.21 \pm 0.72 \dagger *$ & $7.62 \pm 1.05 \dagger \S$ \\
\hline & $\mathrm{V}$ & $0.90 \pm 0.33$ & $3.99 \pm 0.43 *$ & $2.13 \pm 0.65 \dagger *$ & $6.68 \pm 0.78 \dagger \S$ \\
\hline & CWI & $0.98 \pm 0.37$ & $3.92 \pm 0.72 *$ & $2.13 \pm 0.67 \dagger *$ & $4.96 \pm 0.77 \dagger \S$ \\
\hline \multirow[t]{3}{*}{$\mathrm{Na}^{+}\left(\mathrm{mmol} . \mathrm{L}^{-1}\right)$} & PAS & $140.44 \pm 1.01$ & $142.37 \pm 1.55 *$ & $140.56 \pm 1.24 \dagger$ & $142.34 \pm 1.53$ \\
\hline & $\mathrm{V}$ & $140.44 \pm 1.01$ & $142.22 \pm 1.49 *$ & $140.22 \pm 1.64 \dagger$ & $142.37 \pm 1.55$ \\
\hline & CWI & $140.67 \pm 0.87$ & $142.29 \pm 1.85 *$ & $140.61 \pm 0.99 \dagger$ & $143.56 \pm 1.79 \dagger$ \\
\hline \multirow[t]{3}{*}{$\mathrm{pH}$} & PAS & $7.40 \pm 0.01$ & $7.38 \pm 0.05$ & $7.39 \pm 0.06$ & $7.31 \pm 0.11$ \\
\hline & V & $7.41 \pm 0.01$ & $7.36 \pm 0.04$ & $7.41 \pm 0.06$ & $7.32 \pm 0.09$ \\
\hline & CWI & $7.41 \pm 0.01$ & $7.35 \pm 0.09$ & $7.40 \pm 0.06$ & $7.27 \pm 0.11 \dagger$ \\
\hline \multirow[t]{3}{*}{$\mathrm{HCO}_{3}{ }^{-}\left(\mathrm{mmol} \cdot \mathrm{L}^{-1}\right)$} & PAS & $24.5 \pm 1.51$ & $18.58 \pm 2.77 *$ & $22.39 \pm 1.50 \dagger$ & $15.56 \pm 2.82 \dagger$ \\
\hline & $\mathrm{V}$ & $25.07 \pm 0.34$ & $18.82 \pm 4.32 *$ & $23.08 \pm 0.35 \dagger$ & $15.81 \pm 4.34 \dagger$ \\
\hline & CWI & $25.69 \pm 1.39$ & $19.16 \pm 3.14 *$ & $23.67 \pm 1.41 \dagger$ & $16.17 \pm 3.13 \dagger$ \\
\hline
\end{tabular}

$V$, Cryovest; $C W I$, cool water immersion; $P A S$, passive recovery.

* significant difference from Pre value $(\mathrm{P}<0.05)$

$\dagger$ significant difference from $\operatorname{Ex} 1(\mathrm{P}<0.05)$

$\$$ significant difference fromCWI $(\mathrm{P}<0.05)$

$\S$ significant difference from the two others groups $(\mathrm{P}<0.05)$ 
Table 2: Mean \pm SD change in physiological variables from post-exercise bout 1 (Ex1)

to the end of exercise bout 2 (Ex2) for each respective recovery mode.

\begin{tabular}{lccc}
\hline & PAS & V & CWI \\
\hline HR $(\mathrm{bpm})$ & $10.0 \pm 0.06$ & $2.0 \pm 0.06 \S$ & $10.0 \pm 0.07$ \\
Sys BP $(\mathrm{mmHg})$ & $11.1 \pm 10.24$ & $19.4 \pm 7.6 \ddagger$ & $3.9 \pm 6.5$ \\
Dia BP $(\mathrm{mmHg})$ & $4.4 \pm 6.82$ & $6.6 \pm 11.4$ & $5.5 \pm 7.6$ \\
Tbody $\left({ }^{\circ} \mathrm{C}\right)$ & $1.5 \pm 0.4 \S$ & $0.6 \pm 0.4 \S$ & $0.1 \pm 0.04 \S$ \\
$\dot{\mathrm{V} O}\left(\mathrm{~L} \cdot \mathrm{min}^{-1}\right)$ & $0.620 \pm-0.013$ & $0.384 \pm 0.004 \S$ & $0.626 \pm 0.043$ \\
$\dot{\mathrm{V}}\left(\mathrm{L} \cdot \mathrm{min}^{-1}\right)$ & $10.0 \pm 0.06$ & $7.9 \pm 0.05 \S$ & $9.9 \pm 0.04$ \\
$\mathrm{La}^{-}\left(\mathrm{mmol} \cdot \mathrm{L}^{-1}\right)$ & $3.35 \pm 0.44 \S$ & $2.69 \pm 0.65 \S$ & $1.03 \pm 0.31 \S$ \\
$\mathrm{Na}^{+}\left(\mathrm{mmol} \cdot \mathrm{L}^{-1}\right)$ & $-0.03 \pm 0.05$ & $0.15 \pm 0.27$ & $1.27 \pm 0.45 \S$ \\
$\mathrm{pH}$ & $-0.07 \pm 0.06$ & $-0.04 \pm 0.07$ & $-0.08 \pm 0.05$ \\
$\mathrm{HCO}^{3-}\left(\mathrm{mmol} \cdot \mathrm{L}^{-1}\right)$ & $-3.02 \pm 0.06$ & $-3.01 \pm 0.06$ & $-3.00 \pm 0.07$ \\
\hline
\end{tabular}

$V$, cryovest; $C W I$, cool water immersion; $P A S$, passive recovery.

$\ddagger$ Significant difference from the CWI group $(\mathrm{P}<0.05)$

$\S$ Significant difference from the two other groups $(\mathrm{P}<0.05)$

\section{FIGURES}

\section{Figure 1: Study Design.}

Blood samples: Pre exercise (Pre), after exercise 1 (Post Ex1), after Recovery (Post R) and after exercise 2 (Post Ex2).
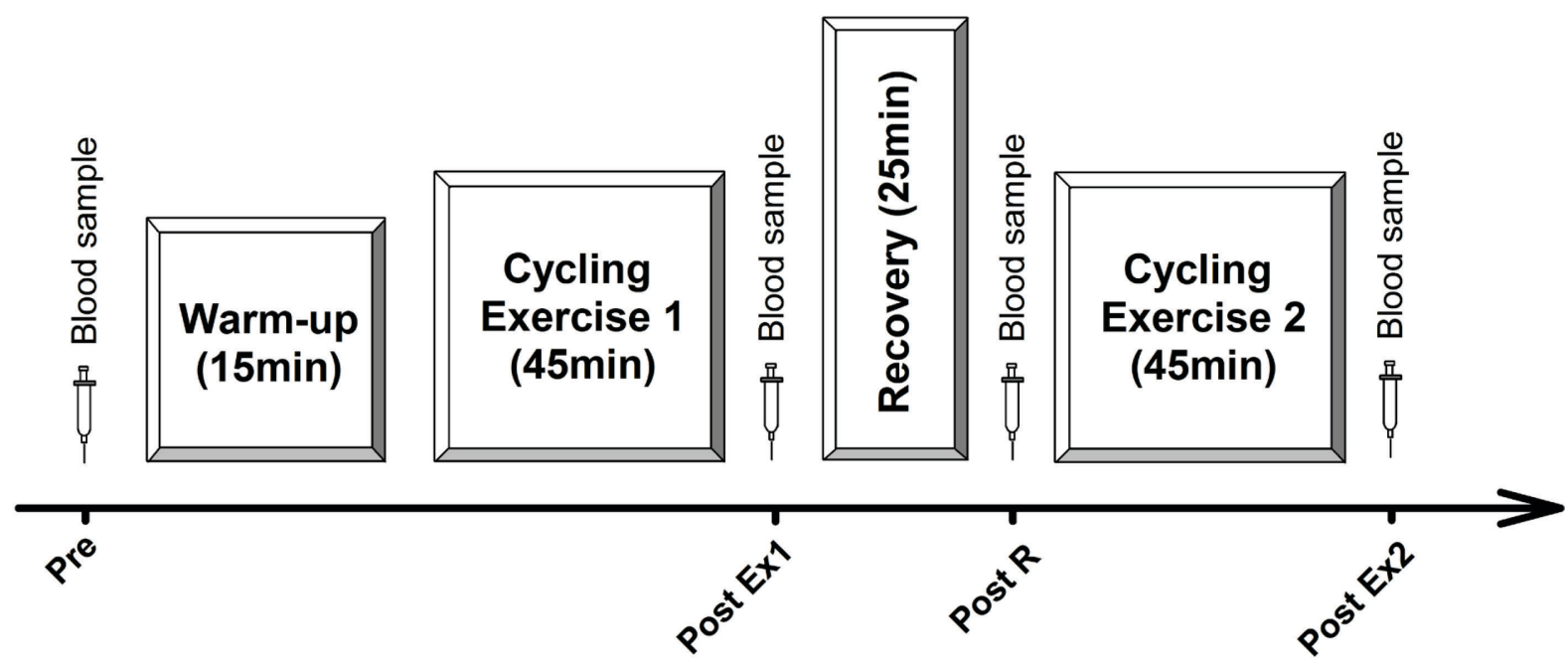
Figure 2: Mean core and skin temperatures at rest (Pre), following exercise bout 1 (Ex1), recovery (R) and exercise bout 2 (Ex2)

$V$, cryovest; $C W I$, cool water immersion; $P A S$, passive recovery.

* significant difference from Pre value $(\mathrm{P}<0.05)$

$\dagger$ significant difference from $\operatorname{Ex} 1(\mathrm{P}<0.05)$

$\$$ significant difference fromCWI $(\mathrm{P}<0.05)$

$\S$ significant difference from the two others groups $(\mathrm{P}<0.05)$
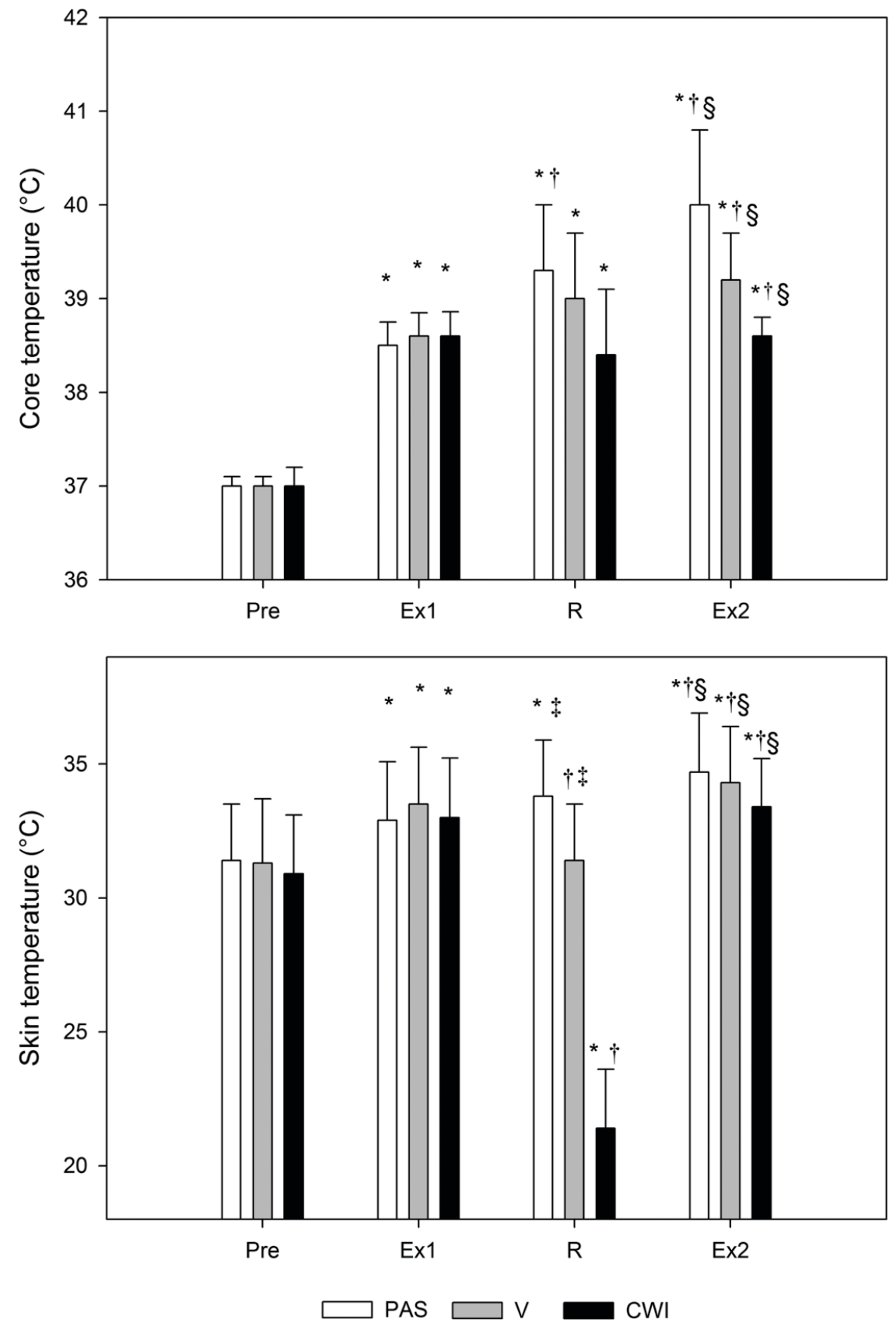
Figure 3: Delta body mass loss between Ex2 and Pre exercise.

$V$, cryovest; $C W I$, cool water immersion; $P A S$, passive recovery.

$\S$ Significant difference from both other groups.

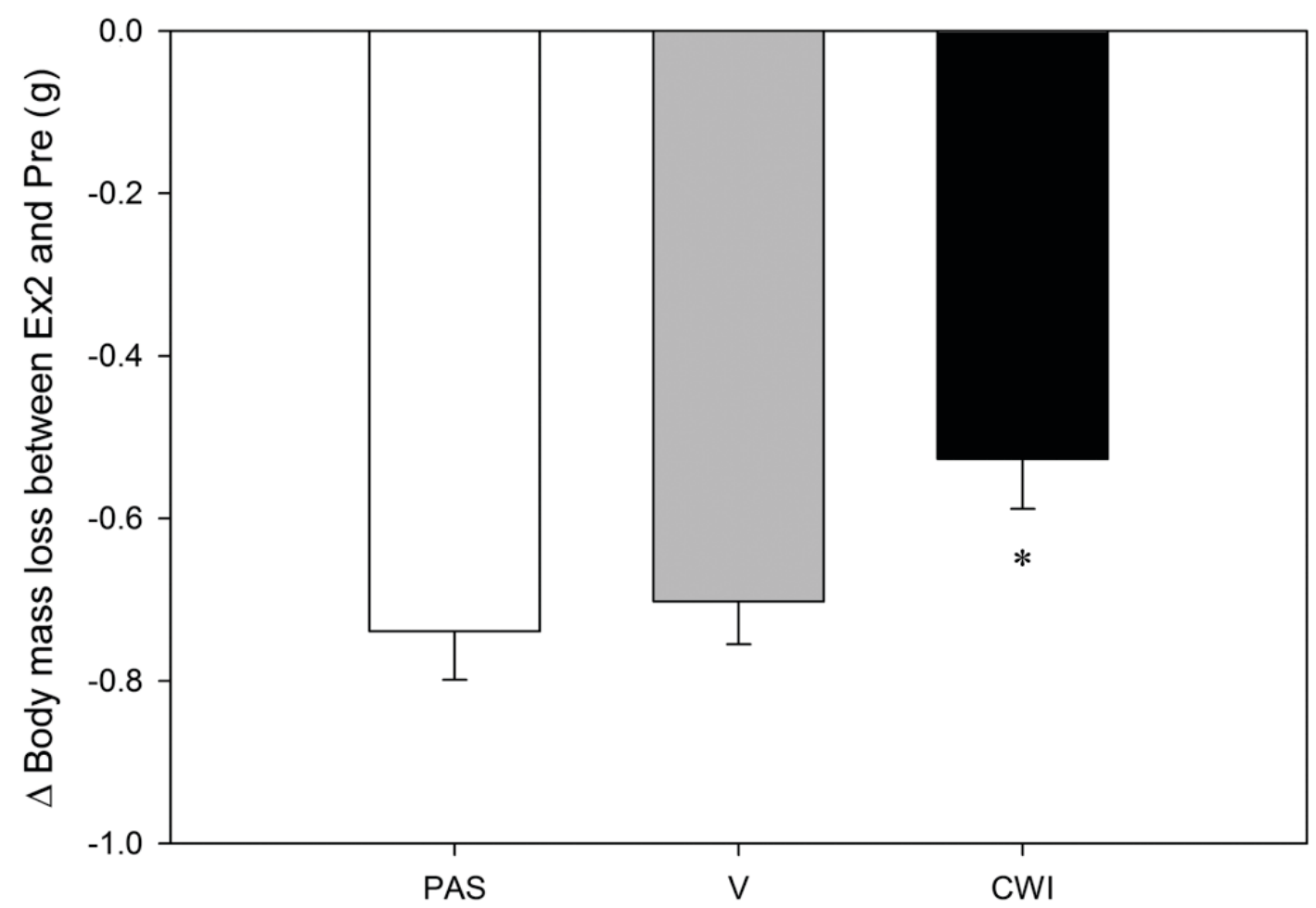

